\title{
A CIDADE-FÁBRICA DE RIO TINTO NA PESQUISA EM DESIGN
}

Luciene Lehmkuhl

Universidade Federal da Paraíba

lucilehmkuhl@hotmail.com

Jeferson Luiz Braz da Silva

Universidade Federal da Paraíba

jefersonzarb@gmail.com

Resumo: Pretendemos expor pesquisa desenvolvida no Departamento de Design da Universidade Federal da Paraíba, cuja primeira ação se deu por meio de uma Iniciação Científica com bolsa UFPB/CNPq (2015-2016), que visava criar um banco de dados para estimular o uso de temáticas locais nas pesquisas em Design. Tomamos os estudos realizados sobre a cidade e sobre a fábrica da Companhia de Tecidos Rio Tinto, do Grupo Lundgren, como ponto de partida e propomos identificar, coletar e analisar dados dos elementos construtivos e ornamentais que compõem a tipologia arquitetônica e urbanística da cidade-fábrica de Rio Tinto, situada no litoral norte da Paraíba. Com a finalização desta primeira etapa da pesquisa são apresentados os resultados elaborados com dados obtidos em levantamento fotográfico e também bibliográfico.

Palavras-chave: Design, História, Cidade-fábrica, Rio Tinto, Industrialização.

Abstract: We intended to expose research developed in Departamento de Design da Universidade Federal da Paraiba, whose first action was through a Iniciação Científica - bolsa UFPB/CNPq (2015-2016), aiming to create a database to encourage the use of local topics in research on design. We take the studies on the city and the factory, Companhia de Tecidos Rio Tinto, of Grupo Lundgren, as a starting point and we propose to identify, collect and analyse data of constructive and ornamental elements that make up the architectural and urban typology of Rio Tinto city factory, located on the northern coast of Paraiba. With the completion of the first stage of the research are presented the results made with data on photo and also bibliographic research..

Keywords: Design; History, City factory, Rio Tinto, Industrialization. 


\section{INTRODUÇÃO}

Em levantamentos iniciais identificamos dificuldades na utilização de dados históricos, sociais, econômicos, culturais e artísticos da cidade-fábrica de Rio Tinto no desenvolvimento de projetos do Curso de Design, instalado no Campus IV da UFPB, na cidade de Rio Tinto, litoral norte da Paraíba. Visando estimular o uso de temáticas locais nos Trabalhos de Conclusão de Curso e demais pesquisas realizadas no Departamento de Design, propomos identificar, coletar e analisar dados dos elementos construtivos e ornamentais que compõem a tipologia arquitetônica e urbanística da cidade-fábrica de Rio Tinto. Tomamos os estudos realizados sobre a cidade e sobre a fábrica da Companhia de Tecidos Rio Tinto, do Grupo Lundgren, como ponto de partida para um estudo inicial realizado com bolsa de Iniciação Científica ${ }^{1}$. Pretendemos, no entanto, avançar nas reflexões apresentadas por pesquisadores oriundos de diferentes áreas do conhecimento, contribuindo com o levantamento, identificação, coleta, sistematização, análise e divulgação de dados, além de estimular pesquisas relacionadas ao tema da cidade-fábrica no âmbito do Curso de Design da UFPB.

Tomado como área de conhecimento, disciplina e profissão que emerge e se estabelece com os primórdios da indústria, tanto no Brasil quanto em outras partes do mundo, o Design tem como característica o diálogo constante com as formas de produção industrial, os trabalhadores da indústria, os usuários dos produtos industriais e, especialmente, os próprios produtos. É, portanto, a industrialização temática de interesse do Design, tanto do seu fazer como da sua história. Ambos, produção de design e história do design fundamentam suas reflexões a partir da noção de projetação para produção em escala industrial e atendimento das necessidades do consumidor/utilizador .

Concordamos com Rafael Cardoso quando afirma que é preciso reconhecer como design as "atividades projetuais com alto grau de complexidade conceitual, sofisticação tecnológica e enorme valor econômico, aplicadas à fabricação, à distribuição e ao consumo de produtos industriais" (CARDOSO,2005, p.8) realizadas no Brasil antes mesmo da década de 1960, quando um novo paradigma é instaurado, surgindo com ele a consciência do design como profissão, a partir da formulação de um novo conceito ligado às vanguardas artísticas e também aos processos de industrialização da segunda metade do século XX.

A cidade-fábrica de Rio Tinto, edificada a partir de 1918 no município de Mamanguape, litoral norte da Paraíba, é caso típico de cidade industrial moderna cuja instalação da fábrica é relacionada ao contexto de transposição de tecnologia industrial britânica que havia se tornado obsoleta e pouco lucrativa no espaço europeu. É possível agregar a estas afirmativas, dados da industrialização no Brasil que relacionam a influência britânica na edificação de cidades e, particularmente, das edificações nas quais foram instaladas as fábricas, os espaços públicos e as casas particulares. Autores costumam vincular estas edificações aos estilos e tipologias arquitetônicas, em seus aspectos construtivos e ornamentais, então em voga na Europa da passagem do século XIX para o XX, situando nas décadas de 1920 e 1930 o

${ }^{1}$ Projeto intitulado Referências urbanas de Rio Tinto para o desenvolvimento de projetos de produtos em Design, aprovado na chamada 2015 do Programa Institucional de Bolsas de Iniciação Científica (PIBIC/CNPq/UFPB), vigência agosto 2015 - julho 2016. 
foco de maior interesse. Encontramos referências ao "padrão britânico Manchesteriano" e ao Art Déco (PANET, 2002, p.59).

Salientamos a importância atribuída por alguns métodos e ferramentas de design às relações estabelecidas entre usuário/produto/designer, ou seja, entre designer e produto, produto e usuário, usuário e designer, rompendo-se as barreiras e alargando-se as fronteiras que, por ventura, ainda insistam em separar cada um desses atores da cena de produção, consumo e circulação dos objetos que compõem a cultura material do mundo no qual vivemos. Logo, uma comunicação em design reside na relação entre pessoas e objetos e não no objeto em si, nem mesmo no trabalho exclusivo do designer. Vale lembrar o pensamento de Gui Bonsiepe, para quem o "design se orienta à interação entre usuário e artefato [sendo que] o domínio do design é o domínio da interface" (BONSIEPE, 1997, p.15).

Esta perspectiva teórica ganha maior valor quando a ela é agregado o aporte da história, especialmente aquela voltada ao estudo da cultura material como meio de acesso às ações humanas no tempo. A perspectiva delineada por Carl Schorske, ao discutir a operação historiográfica e o mundo do historiador, indica a necessidade do diálogo com parceiros de outras áreas para acessar os saberes e os fazeres elaborados por técnicos e artistas que construíram representações de seus mundos (SCHORSKE, 2000). O autor propõe, situar e interpretar as obras no cruzamento entre sincronia e diacronia, procurando abarcar as conexões com outras obras da mesma categoria ou tipologia em diferentes temporalidades, assim como, as conexões entre diferentes obras em uma mesma temporalidade (SCHORSKE, 1988, p.17).

\section{DESENVOLVIMENTO}

\section{Rio Tinto, manchesteriano e Art déco?}

No decorrer da pesquisa as atividades de coleta de dados foram realizadas por meio de levantamento bibliográfico e também da coleta de imagens fotográficas oriundas do espaço urbano da cidade-fábrica de Rio Tinto. Em levantamento bibliográfico inicial listamos livros, teses, dissertações, monografias, artigos em periódicos e textos publicados em anais de eventos, cujas leituras tem confirmado a necessidade de aprofundamento das pesquisas relacionadas à cidade-fábrica, especialmente numa perspectiva da história do design.

Tomamos os textos que integram o livro organizado por Panet (2002), como condutor das questões inicialmente levantadas. Eles nos possibilitaram identificar aspectos da cultura visual e material do espaço urbano e fabril, levando-nos a formular questões que apontam para aspectos no âmbito do design, sua história e seu ensino. Inicialmente nos interessamos em conhecer os elementos que compõem a materialidade das edificações da cidade-fábrica de Rio Tinto, investigando suas conexões com estilos arquitetônicos e artísticos aplicados em cidades e fábricas que tenham servido como modelo ou simplesmente se assemelhem ao caso de Rio Tinto. Neste aspecto, a bibliografia existente auxilia na identificação desses elementos, sem no entanto abordar mais detalhadamente os modelos geradores.

O "padrão manchesteriano" é apontado na bibliografia como empregado na cidade de Rio Tinto (PANET, 2002, p.59), também existente nas edificações de outras cidades-fábricas do período, pode ser caracterizado como de "fachadas erguidas em 
tijolos aparentes que encobrem estruturas moduladas de concreto armado e/ou estruturas importadas de ferro" (DA COSTA, 2013).

São ainda apontadas referências às "fachadas que conciliam tendências 'art déco' ou de arquitetura moderna com uma estética industrial despojada" (GUNN, Philip; CORREIA, Telma, 2002, p.157). Constatamos na bibliografia consultada que o Art Déco ganhou força entre os edifícios fabris brasileiros, principalmente após 1930. A ausência de uma doutrina teórica vinha ao encontro do pragmatismo da produção desses edifícios. Além disso, a sua lógica construtiva era perfeitamente adaptável ao programa industrial - plantas flexíveis, estruturas em concreto, técnicas construtivas tradicionais misturadas com modernas, geometria simplificada, ornamentos contidos (DA COSTA, 2013) .

Assim, conhecer aspectos formais e estilísticos dessas tipologias construtivas, e relacionar os elementos presentes em Rio Tinto com aspectos observados em outras regiões do Brasil, da Europa e das Américas, tem levado a definições mais precisas das características formais dos elementos utilizados. A recolha de dados visuais é de extrema importância nesta pesquisa, permitindo realizar análises a partir de comparações feitas entre as amostras visuais de cidades-fábricas existentes em outras locais e disponíveis na bibliografia.

Nas imagens fotográficas apresentadas abaixo é possível visualizar aspectos dos exemplos citados neste texto. Durante a pesquisa identificamos o uso do tijolo aparente como elemento construtivo e também ornamental em grande parta das edificações da cidade destinadas tanto ao uso comum, como a igreja, os galpões da fábrica, o cine-teatro, o hospital, a cadeia, quanto ao uso particular dos diretores, gerentes e dos proprietários da fábrica, como os dois palacetes e os chalés. Observamos também que nas colunas, vigas e paredes o ferro é utilizado como elemento estrutural. Chama-nos atenção o delicado trabalho realizado com tijolos aparentes nos acabamentos e elementos decorativos, criando ornamentos com formas geométricas e figurativas em elevado grau de detalhamento e acabamento. Os tijolos de argila em diversificados tons que variam do vermelho ao preto, passando pelos alaranjados e amarelos, são alinhados em fileiras regulares e sobrepostos de maneira desencontrada. São assentados com argamassa composta com barro e recebem acabamento de contorno com argamassa pigmentada de branco, elemento que confere às edificações certo caráter higiênico e ordeiro. Vale destacar ainda que os tijolos foram produzidos pela própria Companhia, em olaria instalada como um dos primeiros empreendimentos realizados na região. Destinada à produção de tijolos de argila e também de telhas em formato colonial e francesa, a olaria chegou a contar com "quatrocentos homens no funcionamento do forno de cal" (MELLO, 2002, p.83), imprimindo nas peças saídas da sua linha de produção a marca Olaria Rio Tinto, ainda encontradas nas edificações da cidade. 


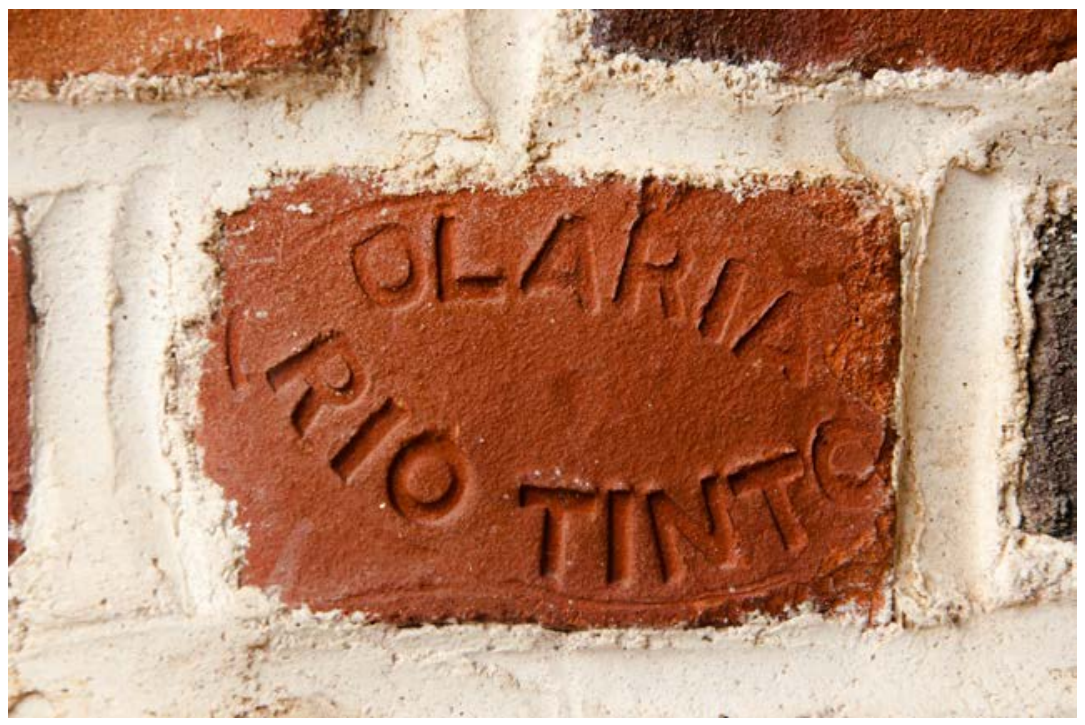

Fig.1 - Marca da Olaria Rio Tinto nos tijolos aparentes existentes nas edificações da Companhia de Tecidos. Rio Tinto, PB.

Fotografia Jeferson Braz, 2016. Acervo dos autores/DDesign/UFPB

Dentre as edificações estudadas, apresentamos a igreja de Santa Rita de Cássia, situada na praça principal da cidade, edificada em 1942 pela Companhia de Tecidos. Suas paredes, colunas, portas, janelas e torre sineira são compostas por tijolos aparentes que criam volumes diversificados, apresentando muitos elementos ornamentais no interior e no exterior da edificação. Destacamos na parte interna da igreja as colunas compostas por tijolos horizontais intercalados gerando forma cilíndrica e, dois elementos exteriores também compostos por tijolos aplicados de diferentes maneiras, com formas figurativas e geométricas de uma lira e uma águia que ornam as paredes da fachada principal, marcando os volumes laterais.

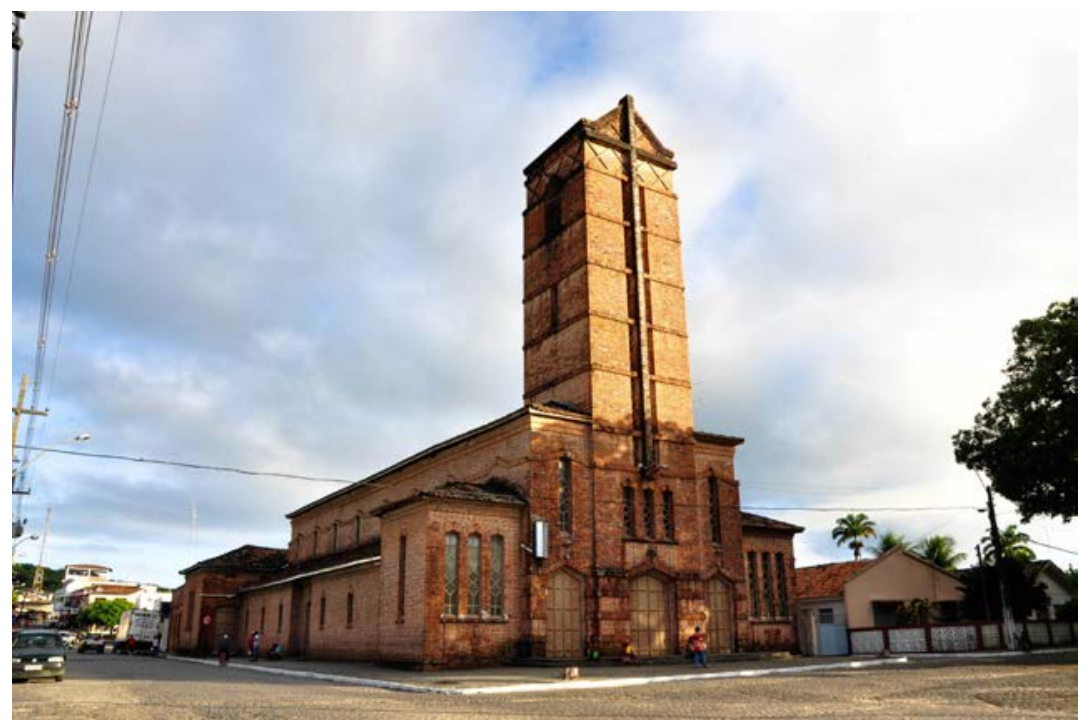

Fig.2 - Fachada da igreja de Santa Rita de Cássia. Rio Tinto, PB.

Fotografia Jeferson Braz, 2016. Acervo dos autores/DDesign/UFPB. 


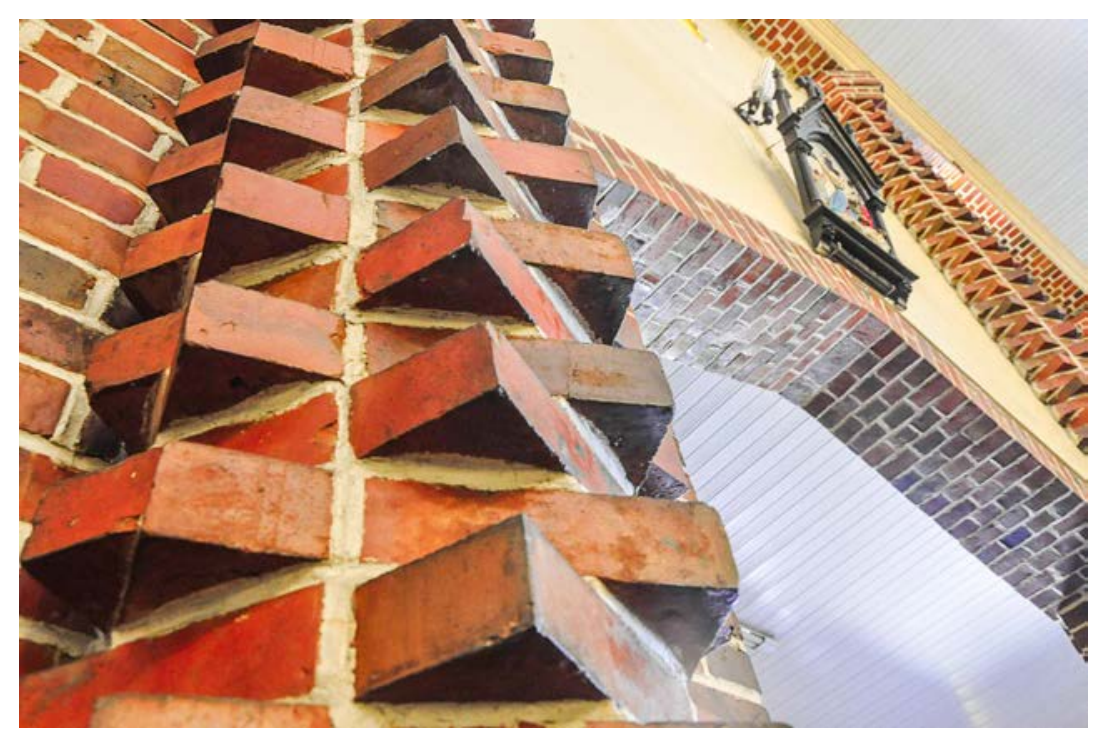

Fig.3 - Colunas da igreja de Santa Rita de Cássia. Rio Tinto, PB.

Fotografia Jeferson Braz, 2016. Acervo dos autores/DDesign/UFPB.
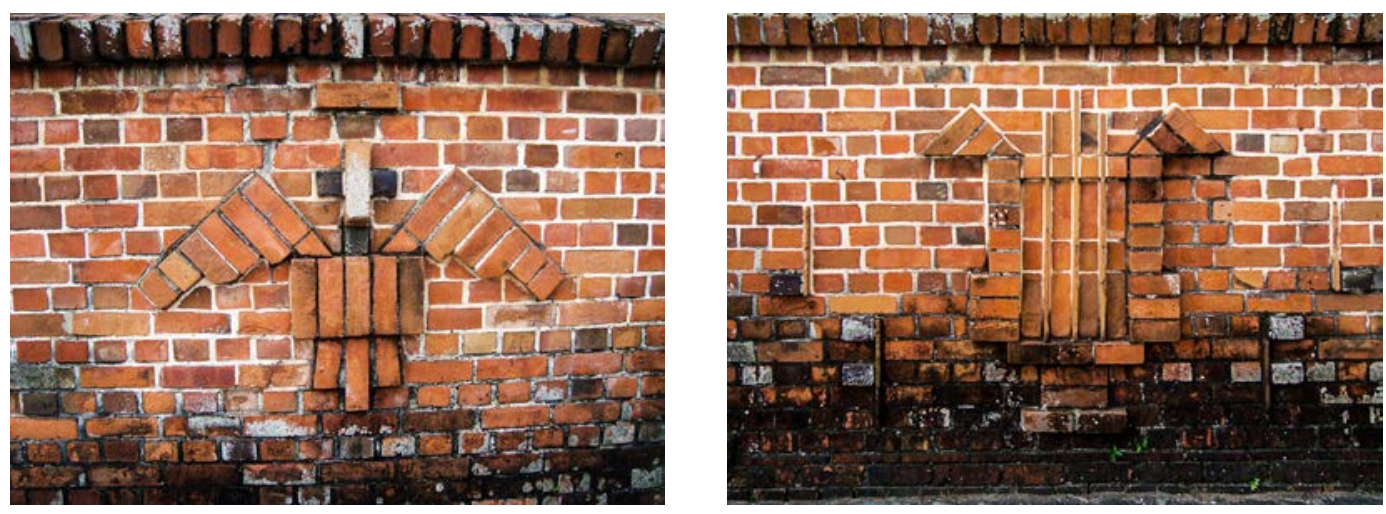

Fig. 4 - Elementos ornamentais na fachada da igreja de Santa Rita de Cássia. Águia. Rio Tinto, PB. Fotografia Jeferson Braz, 2015. Acervo dos autores/DDesign/UFPB.

Fig. 5 - Elementos ornamentais na fachada da igreja de Santa Rita de Cássia. Lira. Rio Tinto, PB. Fotografia Jeferson Braz, 2015. Acervo dos autores/DDesign/UFPB.

O Rio Tinto Tênis Clube constituiu-se como o "eixo da vida social riotintense" (MELLO, 2002, p.111) entre meados dos anos de 1940 e início de 1960, atualmente suas instalações estão bastante descaracterizadas e não se tornaram objeto do estudo que realizamos, no entanto, chamou-nos atenção o letreiro instalado no portão de acesso ao clube. Foram utilizados tipos com características Art Déco, notadamente presentes nas linhas geométricas oriundas do uso do círculo, do quadrado e do triângulo, na regularidade formal alcançada, bem como, na simultânea robustez e elegância que imprimem à fachada do clube. 


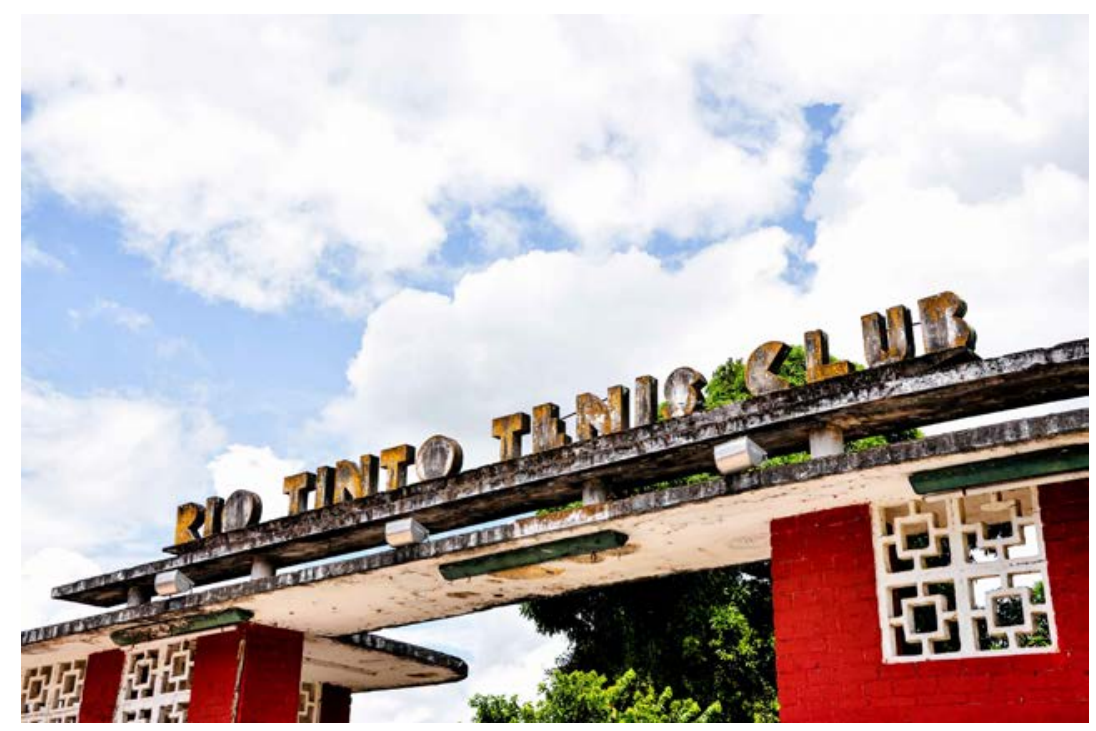

Fig. 6 -- Letreiro com tipos Art déco, fachada do Rio Tinto Tênis Clube. Rio Tinto, PB. Fotografia Jeferson Braz, 2016. Acervo dos autores/DDesign/UFPB.

O cine-teatro Orion, atualmente utilizado como casa de shows, foi inaugurado em 1944 , possui vão central de $36 \mathrm{~m} 2$ com tesouras de cimento armado e laterais abertas com colunas que sustentam o telhado, um palco, cabine de projeção e capacidade para aproximadamente 1.600 lugares. O tijolo aparente é elemento principal das colunas e paredes, compondo a fachada com destaque aos volumes e aos elementos em repetições. O frontão triangular é definido por colunas escalonadas ao centro e nas laterais, estabelecendo a simetria do bloco central. Os tijolos são assentados em diferentes posições, imprimindo leveza ao acabamento.

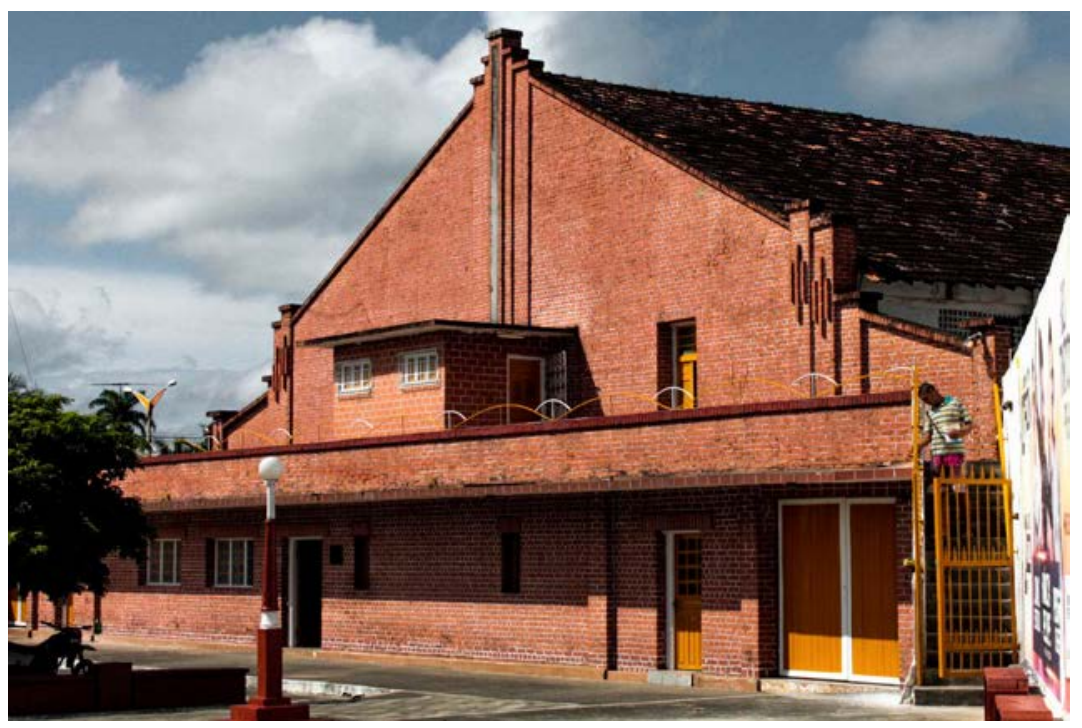

Fig. 7 - Elementos escalonados em tijolos aparentes.

Fachada do antigo Cine-Teatro Orion, atualmente casa de shows. Rio Tinto, PB. Fotografia Leandro Lopes Pereira, 2016. Acervo dos autores/DDesign/UFPB. 
As diversas edificações que fizeram ou fazem parte das instalações fabris, como os galpões, nos quais foram instalados os maquinários e funcionaram diferentes setores da fábrica de tecidos, como fiação, tecelagem, oficinas, etc, também foram edificados com tijolos aparentes. Apresentamos como exemplo uma edificação oriunda da fábrica, atualmente desativada e utilizada como instalação da Universidade Federal da Paraíba. Nela observamos o uso dos tijolos aparentes nas paredes e, especialmente na composição da fachada com quatro aberturas em vidro e cinco colunas estruturais criando volumetrias escalonadas, nas quais os tijolos são assentados nas posições horizontal e vertical, imprimindo ritmo e criando dinâmica à edificação.

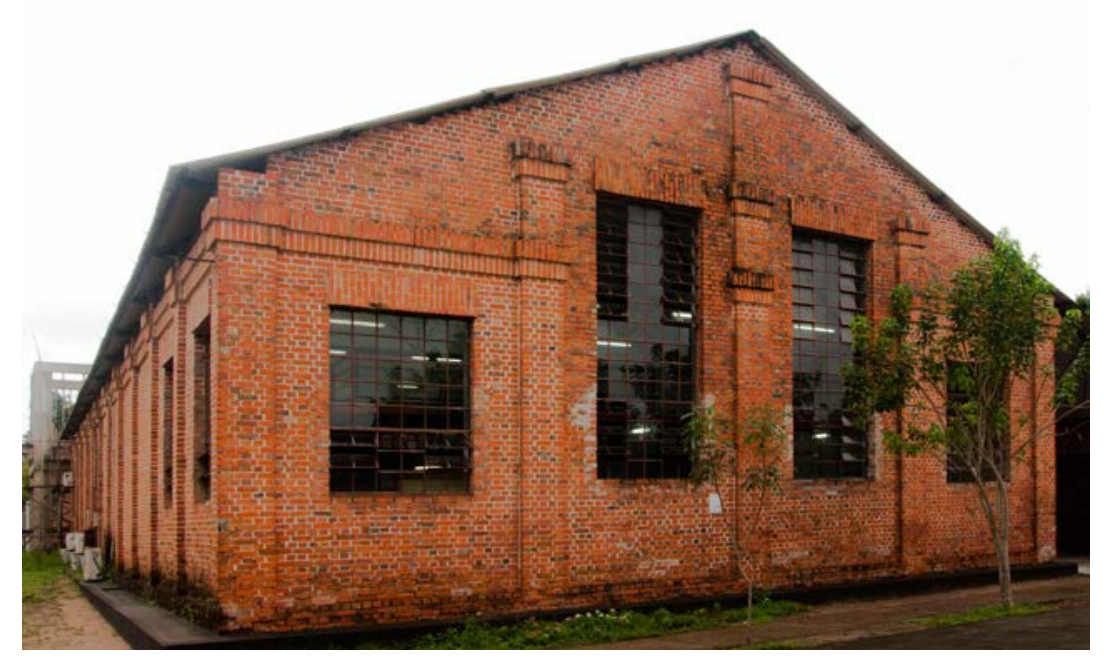

Fig. 8 - Edificação da antiga Fábrica da Companhia de Tecidos Rio Tinto. Rio Tinto, PB.

Fotografia Jeferson Braz, 2016. Acervo dos autores/DDesign/UFPB.

O uso do método comparativo proposto pelo historiador da arte Aby Warburg, em seu Atlas Minemosyne (2010), é princípio que permite fazer aproximações identificando semelhanças e analogias entre as edificações da cidade-fábrica de Rio Tinto com elementos presentes em outras cidades e outras fábricas, erguidas em temporalidades próximas ao caso estudado. Os exemplos aqui apresentados permitem verificar que Rio Tinto não foi caso isolado, sendo até mesmo sua localização geográfica, elemento importante na caracterização deste tipo de edificação. Kempter afirma que não apenas a planta e elevação são responsáveis por definir o caráter do edifício, mas também sua implantação, "próxima a fontes de energia, como os rios, e conectada à linha férrea, principal meio de transporte e elemento essencial para o escoamento da produção e para a alimentação da fábrica com sua matéria-prima." (KEMPTER, 2012, p.6). No caso de Rio Tinto o terreno escolhido para a implantação da cidade-fábrica encontra-se cercado por rios servidos por região portuária, que também se conectam com espaços produtores de matéria prima, como a madeira e o algodão.

Caso bastante semelhante e estudado pela autora citada é a Companhia Nacional de Tecidos Nova América, na zona oeste da cidade do Rio de Janeiro, cujas edificações foram construídas "em um modelo arquitetônico caracterizado pela predominância de grandes fachadas em alvenaria de tijolos aparentes, típico do estilo inglês manchesteriano." (KEMPTER, 2012, p.18) 

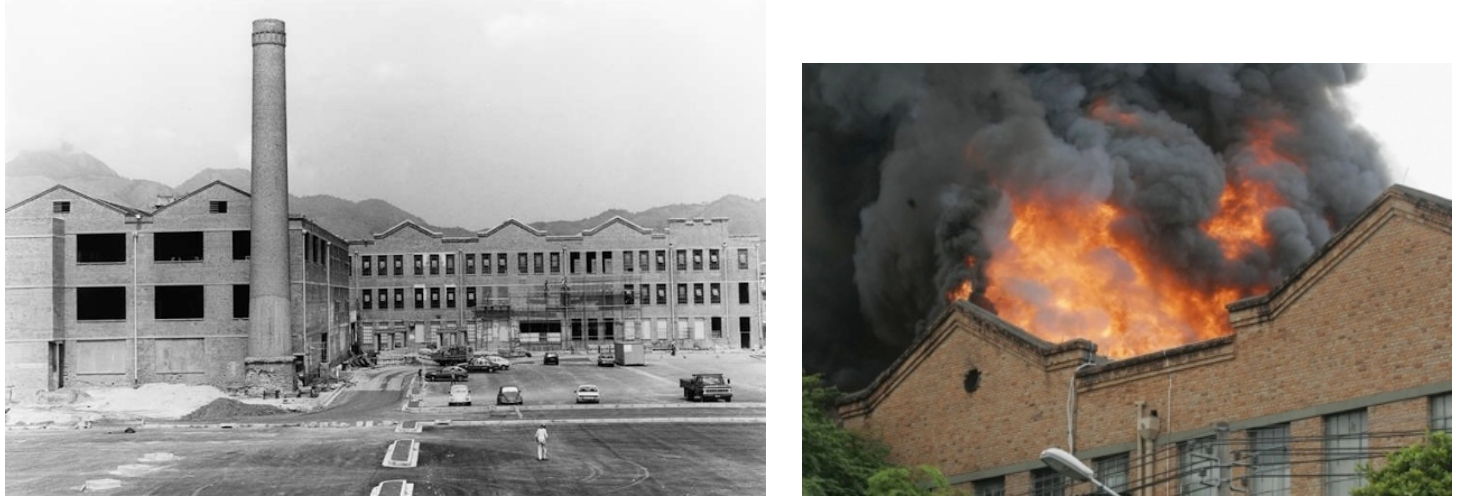

Fig.9 - Instalações da Companhia de Tecidos Nova América, desativadas em 1991. Disponível em: http://www.novaamerica.com.br/card/historico-1991, Acesso em: 16 maio 2016.

Fig.10 - Detalhe do Shopping Nova América, zona norte do Rio de Janeiro, RJ. A fotografia apresenta incêndio ocorrido em 16/02/2015. Instalações da antiga Cia. Nacional de Tecidos Nova América.

Outro caso de interesse para este estudo é a fábrica MAESA de Caxias do Sul, cujas instalações foram declaradas patrimônio histórico da cidade, em janeiro de 2015. MAESA é a sigla para Metalúrgica Abramo Eberle Sociedade Anônima, cuja fábrica implantada em 1948, possuía forja, fundição e fabricação de talheres. No detalhe apresentado na figura 12, é possível observar a semelhança com as edificações de Rio Tinto nas aberturas em vidro, nas colunas e, especialmente no uso dos tijolos aparentes em diferentes posições, criando ornamentos nas fachadas. Da Costa (2013), citada neste texto, relaciona este sistema construtivo ao estilo machesteriano.

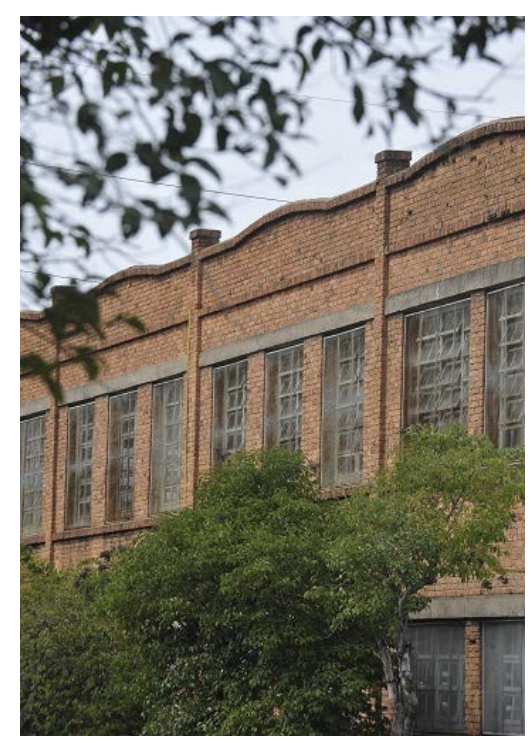

Fig.11 - Detalhe de edificação do complexo da fábrica MAESA. Caxias do Sul, RS.

Disponível em: http://wp.clicrbs.com.br/memoria/2014/05/19/nos-primordios-damaesa/?topo=35/page/3/ , Acesso em: 16 maio 2016.

Vale ainda apontar as características Art Déco identificadas em edificações de caráter público ou particular e equipamentos de lazer, existentes na cidade de Paris, cujo uso do tijolo aparente pode ser comparado ao caso de Rio Tinto. O uso de tijolos aparentes na arquitetura francesa, e especialmente na parisiense, que havia se 
tornado fora de moda no século XIX, encontrou nova utilização no início do século XX, principalmente, na década de 1930 com as edificações de habitações sociais, edifícios industriais, de lazer e igrejas.

Observemos as paredes e fachadas de edificações localizadas em dois diferentes "quartiers" parisienses, uma destinada à ocupação com atelieres de artistas, a outra destinada à prática esportiva e ao lazer, ambas datadas do início da década de 1930. Estas edificações apresentam elementos ornamentais semelhantes aqueles encontrados nas edificações da cidade-fábrica de Rio Tinto, com tijolos assentados em diferentes posições, criando padrões ornamentais no próprio plano da parede, em relevos e vazados.

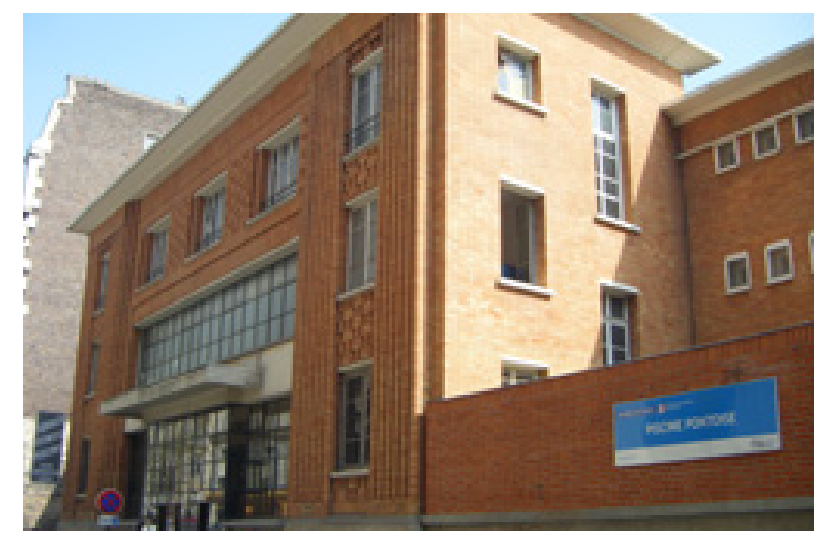

Fig.12 - Fachada da Piscina da rua de Pontoise, 5e, Paris. Edificado em 1934.

In: PLUM, Paris Art déco, 2008, p.139.

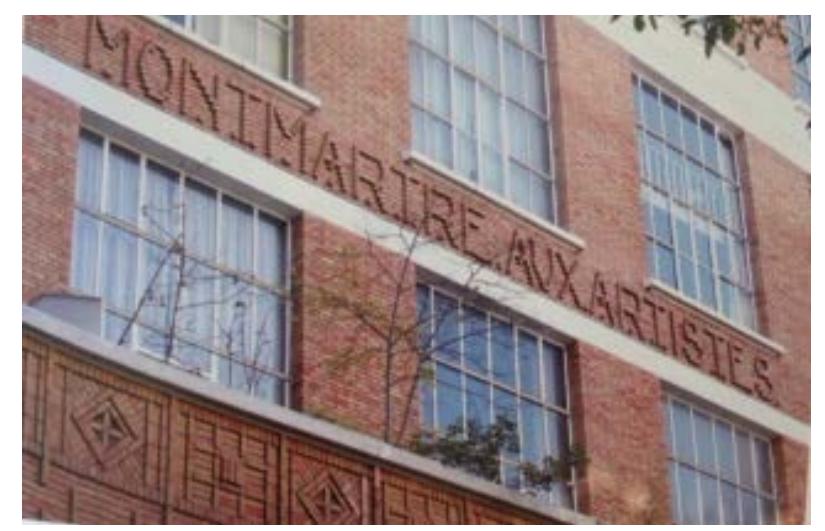

Fig.13 - Fachada de Montmartre-aux-Artistes, 18e, Paris. Edificado entre 1930 e 1932.

In: PLUM, Paris Art déco, 2008, p.95. 


\section{CONCLUSÃO}

As reflexões desenvolvidas neste texto foram possíveis devido ao uso dos dados obtidos com a pesquisa realizada como iniciação científica, citada acima. Nela, inicialmente, foram capturadas imagens com uma câmera digital comum, em passeios pela cidade, seguindo os roteiros de edificações apontados na bibliografia consultada. Estas fotografias tiveram o objetivo de identificar a existência das edificações e seu estado de conservação, quando comparadas às fotografias publicadas, especialmente no livro de Panet (2002). Com a análise destas imagens foram definidos horários, perspectivas e ângulos mais adequados para a realização de fotografias com equipamento profissional, posteriormente tratadas e disponibilizadas em banco de dados contendo imagens e textos, estes produzidos a partir de pesquisa bibliográfica.

Acreditamos que o material oriundo da pesquisa e disponibilizado à comunidade acadêmica da UFPB, poderá proporcionar inúmeras pesquisas em diferentes direções, muitas delas relacionadas ao design e sua história. O recorte aqui apresentado limitou-se a discutir aspectos construtivos e ornamentais das edificações encontradas na cidade-fábrica de Rio Tinto. No entanto, outros temas de pesquisa estão sendo desenvolvidos no Curso de Design, seja em iniciação científica, em trabalhos de conclusão de curso e outros projetos. Apontamos especialmente estudos em história do design englobando o desenvolvimento de projetos e a produção ocorridos na fábrica da Companhia de Tecidos Rio Tinto, bem como, o desenvolvimento de projetos de produtos como embalagem e jogos relacionados à valorização da cultura e patrimônio locais.

\section{REFERÊNCIAS}

BONSIEPE, Gui. Design: do material ao digital. Trad. Cláudio Dutra. Florianópolis: FIESC/IEL, 1997.

CARDOSO, Rafael (org.). O Design Brasileiro antes do Design: aspectos da História Gráfica - 1870 - 1960. Cosac Naify. 2005.

COSTA, Francisco de Barros. Os Lundgren e o fenômeno da industrialização em Rio Tinto - Paraíba. s/e., s/l., 1996. Monografia.

DA COSTA, Ana Elisia. A poética dos tijolos aparentes e o caráter industrial - MAESA (1945). IV Seminário Docomomo Sul. Porto Alegre, 25 a 27 março 2013. Disponível em:

http://www.docomomo.org.br/ivdocomomosul/pdfs/06\%20Ana\%20Elisia\%20Costa.pd f. Acesso em: 15 maio 2015.

DANTAS, Anna Alice Roque Santana. Rio Tinto, Impacto do declínio econômico na organização espacial. Dissertação (Mestrado em Engenharia Urbana) PPGEU - Centro de tecnologia, Universidade Federal da Paraíba, João Pessoa. 2009, 102 f.

GUNN, Philip; CORREIA, Telma. O habitat operário no nordeste industrial: os núcleos fabris de Paulista e Rio Tinto. In: PANET, Amélia; et al. Rio Tinto: estrutura urbana, trabalho e cotidiano. João Pessoa: UNIPÊ editora, 2002, pp. 137-161.

LÖBACH, Bernd. Design Industrial: bases para a configuração dos produtos industriais. São Paulo: Edgard Blücher, 2001. 
MELLO, José Octávio. Arqueologia industrial e o cotidiano em Rio Tinto. In: PANET, Amélia; et al. Rio Tinto: estrutura urbana, trabalho e cotidiano. João Pessoa: UNIPÊ editora, 2002, pp.65-122.

PANET, Amélia; et al. Rio Tinto: estrutura urbana, trabalho e cotidiano. João Pessoa: UNIPÊ editora, 2002.

RAMOS, Leandro da Silva. et al. Cidade-Fábrica Rio Tinto cenário de influências no processo de produção do espaço paraibano. Disponível em: < http://www.webartigos.com/artigos/cidade-fabrica-rio-tinto-cenario-de-influenciasno-processo-de-producao-do-espaco-paraibano/47419/>. Acesso em: 15 out. 2015.

ROITER, Márcio Alves. Pindorama modernista: influência indígena no art déco brasileiro. Culturas indígenas. Brasília: Ministério das Relações Exteriores, 2012, p.7489. (Textos do Brasil 19)

ROSA, Carolina Lucena. Nada de preguiça: em 1924, uma fábrica de tecidos se instalou no interior da Paraíba, era "uma ativa colmeia operária". Disponível em:

$<$ http://www.revistadehistoria.com.br/secao/artigos/nada-de-preguica>. Acesso em: 15 out. 2015.

ROSI, Lia Mônica. Art Déco sertanejo e uma revitalização possível: programa Campina Grande Déco. Revista UFG, ano XII, n. 8, jul.2010, pp. 28-34.

SANTANA, Anna Aline Roque. Rio Tinto: cultura, lazer e turismo. João Pessoa. s/e., 2006.

SCHORSKE, Carl. Pensando com a história: indagações na passagem para o modernismo. São Paulo: Companhia das Letras, 2000.

SCHORSKE, Carl. Viena fin-de-siècle: política e cultura. São Paulo: Companhia das Letras, 1988.

SILVA, Lígia Maria Tavares da. Características da urbanização na Paraíba. Revista

Cadernos do Logepa: série texto didático, João Pessoa, v. 3, n. 5, 34-39, jul./dez. 2004. Disponível em: <http://periodicos.ufpb.br/ojs/index.php/logepa/article/view/11009>. Acesso em: 02 out. 2015.

VALE, Eltern Campina. Os usos da Justiça na busca por direitos: estratégias de reivindicação operária na cidade-fábrica Rio Tinto (Paraíba, 1959-1964). Revista Mundos do Trabalho, Fortaleza, v. 2, n. 3, p. 261-280, jan./jul. 2010. Disponível em: <http://dx.doi.org/10.5007/1984-9222.2010v2n3p261>. Acesso em: 07 out. 2015.

VALE, Eltern Campina. Tecendo fios, fazendo história: A atuação operária na cidadefábrica Rio Tinto (Paraíba, 1959-1964). 2008. 225 f. Dissertação (Mestrado em História Social) - Centro de Humanidades, Universidade Federal do Ceará, Fortaleza. 2008.

KEMPTER, Eloisa Dezen. Territórios Fabris Resilientes: Cinco Casos a Considerar. VI Colóquio Latino Americano sobre Recuperação e Preservação do Patrimônio industrial, 2012. Disponível em: <http://portal.iphan.gov.br/portal/baixaFcdAnexo.do?id=2980>. Acesso em 20 de Dezembro de 2014.

WARBURG, Aby. Atlas Mnemosyne. Madrid: Akal, 2010. (Arte y estética -77) 